Tropical Journal of Pharmaceutical Research September 2020; 19 (9): 1857-1862

ISSN: $1596-5996$ (print); 1596-9827 (electronic)

(C) Pharmacotherapy Group, Faculty of Pharmacy, University of Benin, Benin City, 300001 Nigeria.

\title{
Anti-inflammatory effect of neo-lignan isoamericanin A via suppression of NF-KB in liposaccharide-stimulated RAW 264.7 cells
}

\author{
Ji Yun Yeo1, Kwang Woo Hwang², So-Young Park ${ }^{1 *}$ \\ ${ }^{1}$ Laboratory of Pharmacognosy, College of Pharmacy, Dankook University, Cheonan 31116, ${ }^{2}$ Host Defense Modulation \\ Laboratory, College of Pharmacy, Chung-Ang University, Seoul 06974, Korea
}

*For correspondence: Email: soypark23@dankook.ac.kr; Tel: +82 415501434

Sent for review: 5 March 2020

Revised accepted: 27 August 2020

\begin{abstract}
Purpose: To investigate the potential anti-inflammatory effects of the seeds of Opuntina humifusa and its active constituents.

Methods: The extract of O. humifusa seeds was tested for the inhibition of nitric oxide (NO) production in liposaccharide (LPS)-stimulated RAW 264.7 cells using Griess reagent. The active constituents were isolated using bioassay-guided isolation methods. The effects of the active constituent on NO, proinflammatory cytokines, nuclear factor-kappa $B$ (NF-kB) and nuclear factor of kappa light polypeptide gene enhancer in B-cells inhibitor (IKB) were evaluated by enzyme-linked immunosorbent assay (ELISA) and western blot analysis.

Results: The seed extract of O. humifusa significantly attenuated LPS-induced NO production in RAW 264.7 cells $(p<0.05)$. Bioassay-guided fractionation resulted in the isolation of isoamericanin $A$ as an active constituent. Isoamericanin $A$ reduced LPS-induced production of NO, iNOS, and proinflammatory cytokines (TNF- $\alpha$ and IL-6) in a concentration-dependent manner $(p<0.05)$. Furthermore, the effect was accompanied by decreased translocation of NF-KB from the cytosol to the nucleus and the decreased phosphorylation of IKB in the cytosol induced by LPS $(p<0.05)$.

Conclusion: The seed extract of $O$. humifusa and its active constituent, isoamericanin $A$, have antiinflammatory effects in LPS-stimulated RAW 264.7 cells, suggesting that they have potentials as antiinflammatory agents.
\end{abstract}

Keywords: Opuntia humifusa seeds, Isoamericanin A, Nitric oxide, RAW 264.7 cells, NF-kappa B

\begin{abstract}
This is an Open Access article that uses a fund-ing model which does not charge readers or their institutions for access and distributed under the terms of the Creative Commons Attribution License (http://creativecommons.org/licenses/by/4.0) and the Budapest Open Access Initiative (http://www.budapestopenaccessinitiative.org/read), which permit unrestricted use, distribution, and reproduction in any medium, provided the original work is properly credited.

Tropical Journal of Pharmaceutical Research is indexed by Science Citation Index (SciSearch), Scopus, International Pharmaceutical Abstract, Chemical Abstracts, Embase, Index Copernicus, EBSCO, African Index Medicus, JournalSeek, Journal Citation Reports/Science Edition, Directory of Open Access Journals (DOAJ), African Journal Online, Bioline International, Open-J-Gate and Pharmacy Abstracts
\end{abstract}

\section{INTRODUCTION}

Opuntia humifusa Raf. (Cactaceae) is a cactus known as the eastern prickly pear. It is widely cultivated in the southern parts of Korea and is locally called Cheonnyuncho. The stems and fruits of $O$. humifusa are used as food worldwide in the form of juice or freeze-dried powder because they are rich in polyphenols, flavonoids, minerals, and dietary fiber. Traditionally, it has been used to treat diabetes, inflammation, and rheumatoid arthritis [1]. In addition, there are reports on its anti-cancer effects on diverse cancer cells including glioblastoma, cervical 
carcinoma, and gastric adenocarcinoma $[2,3]$. 0 . humifusa has antibacterial [4], and anti-fungal [5] effects, and increases insulin sensitivity [6]. The inhibitory effect of $O$. humifusa against LPSinduced inflammation has also been reported $[7,8]$.

However, studies on the biological activities of $O$. humifusa focused mainly on the stems and fruits; the properties of its seeds have not been studied yet. Thus, in this study, the anti-inflammatory effects of $O$. humifusa seeds were examined and their active constituent was isolated using bioassay-guided fractionation. The antiinflammatory mechanisms of the active constituents were also elucidated.

\section{EXPERIMENTAL}

\section{Chemicals and reagents}

Dulbecco's modified Eagle's medium (DMEM), and fetal bovine serum (FBS) were obtained from Welgen (Korea). Griess reagent, 3-(4,5dimethylthiazol -2-yl)-2,5-diphenyl-tetrazolium bromide (MTT), LPS, and dimethyl sulfoxide (DMSO) were purchased from Sigma Aldrich (CA, USA).

\section{Preparation of the seed extract and isolation of isoamericanin A}

The seeds of $O$. humifusa were collected after removing the flesh of the fruits. The seeds $(3 \mathrm{~kg})$ were pulverized and extracted with $80 \%$ methanol $(\mathrm{MeOH})$. The $\mathrm{MeOH}$ filtrate was concentrated under vacuum, yielding $150 \mathrm{~g}$ of $\mathrm{MeOH}$ extract. The $\mathrm{MeOH}$ extract was suspended in distilled water and sequentially partitioned into $n$-hexane $(2.2 \mathrm{~g})$, chloroform (6.7 $\mathrm{g})$, EtOAc $(7.2 \mathrm{~g}), n-\mathrm{BuOH}(8.0 \mathrm{~g})$ and water $(19.3 \mathrm{~g})$. Each fraction was dissolved in DMSO for the bioassay. The chloroform fraction was subjected to open column chromatography and eluted with chloroform-MeOH (100:0 to 1:1) to give 12 sub-fractions (OCC1 OCC12). The subfraction OCC5 (0.2 g) was further purified by semi-preparative HPLC and eluted with acetonitrile (ACN)- $\mathrm{H}_{2} \mathrm{O}$ (30 to $60 \% \mathrm{ACN}$ gradient) to yield compound 1 (15.2 $\mathrm{mg})$. Compound 1 was identified as isoamericanin A based on the NMR and MS data compared with previously published data [9].

\section{Cell culture}

RAW 264.7 cells obtained from Korea Cell Line Bank (Seoul, Korea) were grown in DMEM supplemented with $10 \%$ FBS under a humidified $5 \% \mathrm{CO}_{2}$ atmosphere at $37{ }^{\circ} \mathrm{C}$. The cells were treated with LPS $(1 \mu \mathrm{g} / \mathrm{mL})$ in the presence or absence of test samples for $24 \mathrm{~h}$.

\section{Evaluation of cell viability}

RAW 264.7 cells plated on 96 -well plates $\left(5 \times 10^{4}\right.$ cells/well) were pre-treated with test samples for $1 \mathrm{~h}$ and incubated with LPS for an additional 24 h. Then, the cells were incubated with MTT (5 $\mathrm{mg} / \mathrm{mL}$ ) for $3 \mathrm{~h}$ followed by DMSO for $30 \mathrm{~min}$ after removing the media. The absorbance was measured at $570 \mathrm{~nm}$ (Molecular Devices, CA, USA). All measurements were done in triplicate and repeated at least three times.

\section{Determination of NO production}

The production of NO was determined using Griess reagent. The cells pre-treated with test samples were incubated with LPS for $24 \mathrm{~h}$. Then, the supernatants were centrifuged at $12,000 \mathrm{rpm}$ for $15 \mathrm{~min}$ and incubated with Griess reagent at $37{ }^{\circ} \mathrm{C}$ for $20 \mathrm{~min}$ in the dark. The absorbance was measured at $540 \mathrm{~nm}$ using a microplate reader.

\section{Western blot analysis}

Proteins $(30 \mu \mathrm{g})$ in cell lysates were separated using denaturing polyacrylamide gel electrophoresis (SDS-PAGE) and electrotransferred onto a PVDF membrane (Millipore, Billerica, MA, USA). The membranes blocked with $5 \%$ nonfat dry milkwere incubated with the following primary antibodies: anti-IKB (1:1000, Cell Signaling, Denver, MA, USA), anti-p-IkB (1:1000, Cell Signaling), anti-lamin A/C (1:1000, Cell Signaling), anti-iNOS (1:1000, Cell Signaling), anti-NF-kB p65 (1:1000, Santa Cruz, Santa Cruz, CA, USA), anti-NF-kB p50 (1:1000, Santa Cruz), and anti- $\alpha$-tubulin (1:1000, Sigma Aldrich). Horseradish peroxidase-conjugated secondary antibodies (1:2000, Santa Cruz), and enhanced chemiluminescence $(E C L)$ reagents (Advantas, CA, USA) were used for detection with the Bio-Rad Imager (Bio-Rad, CA, USA). Densitometric values were normalized with those of lamin $\mathrm{A} / \mathrm{C}$ and $\alpha$-tubulin as internal controls. The cytoplasmic and nuclear extracts were prepared with a Nuclear and Cytoplasmic Kit (Thermo Scientific, CA, USA) based on the manufacturer's instructions.

\section{Enzyme-linked immunosorbent assay (ELISA)}

The supernatants were collected from RAW cells after treatment with LPS for $24 \mathrm{~h}$ in the presence or absence of isoamericanin A $(1,2$, or $4 \mu \mathrm{g} / \mathrm{mL})$, and the production of cytokines was evaluated using ELISA [10] employing the following capture 
antibodies: TNF- $\alpha$ and IL-6 (BD Biosciences, San Jose, CA, USA). The absorbance was measured at $405 \mathrm{~nm}$ using a microplate reader. Cytokines were quantified based on a standard curve.

\section{Statistical analysis}

All data are presented as mean \pm SD $(n=3)$. One-way analysis of variance (ANOVA) followed by Tukey's post-hoc test was employed for comparisons of two or more groups. Differences were considered statistically significant at $p<$ 0.05 .

\section{RESULTS}

\section{Inhibitory effect of $O$. humifusa seed extract} on NO production

The possible cytotoxicity of the methanol $(\mathrm{MeOH})$ extract of $O$. humifusa seeds was tested by MTT assay. As shown in the results, the $\mathrm{MeOH}$ extract of $O$. humifusa seeds did not decrease the viability of RAW cells at up to $20 \mu \mathrm{g} / \mathrm{mL}$. However, $20 \mu \mathrm{g} / \mathrm{mL} \mathrm{MeOH}$ extract reduced LPSinduced NO production by $50 \%$ compared to that in the LPS-treated control groups (Figure 1). Thus, the $\mathrm{MeOH}$ extract was further partitioned by solvent polarity into four sub-fractions ( $n$ hexane, chloroform, ethyl acetate and water). The sub-fractions were subjected to the MTT assay to evaluate possible cytotoxicity. Three sub-fractions (chloroform, ethyl acetate and water) did not alter the viability of RAW cells, whereas the $n$-hexane fraction significantly reduced the viability (Figure $1 \mathrm{~A}$ ). Thus, the $n$ hexane fraction was excluded from further studies. Then, three sub-fractions $(20 \mu \mathrm{g} / \mathrm{mL})$ were evaluated for their effects on LPSstimulated NO production in RAW cells. The chloroform fraction significantly reduced $\mathrm{NO}$ production compared to that of the control group (Figure $1 \mathrm{~B}$ ), whereas the ethyl acetate fraction exhibited only a weak inhibitory effect. Thus, the chloroform fraction was studied further to identify the active components.

\section{Inhibition of NO production by isoamericanin A}

To obtain active constituents in the chloroform fraction of the $O$. humifusa seed extract, bioassay-guided isolation was performed using silica gel column chromatography and semipreparative HPLC. Based on these results, isoamericanin $A$ was isolated as an active constituent from the chloroform fraction (Figure 2 A). The possible cytotoxicity of isoamericanin $A$ was determined by the MTT assay. At up to 4 $\mu \mathrm{g} / \mathrm{mL}$, isoamericanin A did not reduce the viability of RAW cells (Figure $2 \mathrm{~B}$ ). Treatment of cells with isoamericanin A significantly attenuated LPS-induced NO production in RAW cells (Figure $2 \mathrm{~B}$ ) in a concentration-dependent manner $(1,2$, and $4 \mu \mathrm{g} / \mathrm{mL})$. Notably, $4 \mu \mathrm{g} / \mathrm{mL}$ isoamericanin A reduced NO production by $60 \%$ compared to that in the LPS-treated group.
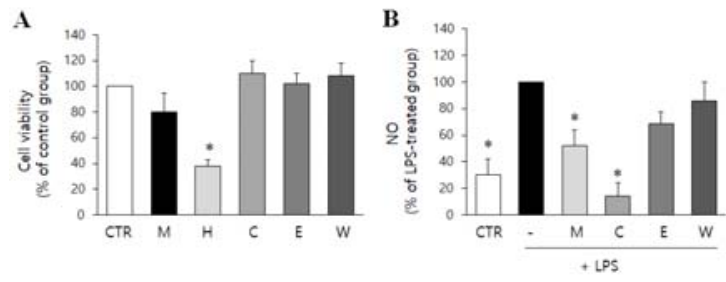

Figure 1: Effect of $O$. humifusa seed extract on the viability of RAW 264.7 cells and NO production. (A) The viability of RAW cells treated with $O$. humifusa seed extract and its four solvent-partitioned fractions $(20 \mu \mathrm{g} / \mathrm{mL})$ for $24 \mathrm{~h}$ was determined by MTT assay. Values are a percentage of the values for the DMSOtreated control groups. (B) NO production with $O$. humifusa seed methanol extract and its sub-fractions $(20 \mu \mathrm{g} / \mathrm{mL})$ of $O$. humifusa seeds was measured with Griess reagent $(\mathrm{M}$ : methanol, $\mathrm{H}$ : $n$-hexane, $\mathrm{C}$ : chloroform, E: ethyl acetate, W: water). Values are a percentage of the values for the LPS-treated groups. Data are presented as mean \pm SD of three different experiments. ${ }^{*} P<0.05$, significantly different from LPS-treated groups, ${ }^{\#} p<0.05$, significantly different from DMSO-treated control groups

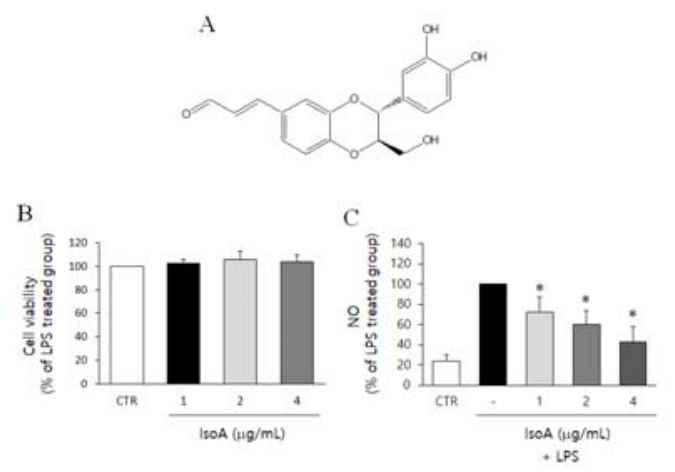

Figure 2: Effect of isoamericanin A (IsoA) on LPSinduced NO production in RAW cells. (A) The structure of isoamericanin $A$ isolated from $O$. humifusa seeds based on bioassay-guided isolation. (B) The viability of RAW cells in the presence of isoamericanin $A(1,2$, and $4 \mu \mathrm{g} / \mathrm{mL}$ ) was determined by MTT assay. Values are expressed as a percentage of values for the DMSO-treated cells. (C) NO production with or without isoamericanin $\mathrm{A}(1,2$, and $4 \mu \mathrm{g} / \mathrm{mL})$ in LPS-stimulated RAW cells was determined with Griess reagent. Values are a percentage of the values for the LPStreated groups. Data are presented as mean \pm SD of three different experiments. ${ }^{*} P<0.05$, significantly different from the LPS-treated groups

Trop J Pharm Res, September 2020; 19(9): 1859 
Inhibition of iNOS and pro-inflammatory cytokine expression by isoamericanin A

iNOS is an enzyme responsible for NO production in RAW cells. The possible change in iNOS expression was determined by western blot analysis. The cells treated with LPS significantly increased the expression of iNOS whereas pretreatment of cells with isoamericanin $A$ prior to LPS treatment reduced the expression of iNOS in a concentration-dependent manner (Figure $3 \mathrm{~A}$ and $\mathrm{B})$ compared to that in the LPS-treated group. In particular, $4 \mu \mathrm{g} / \mathrm{mL}$ of isoamericanin $A$ decreased iNOS levels to close to the controlgroup level. This result is consistent with the inhibitory effects of isoamericanin $A$ on $\mathrm{NO}$ production as described above.

In addition, the secretion of pro-inflammatory cytokines TNF- $\alpha$ and IL- 6 by RAW cells was determined by ELISA. As shown in Figure $3 \mathrm{C}$ and D, LPS treatment of RAW cells significantly increased the concentration of TNF- $\alpha$ and IL- 6 in the supernatant whereas pre-treatment with isoamericanin A prior to LPS treatment significantly reduced the levels of cytokines in a concentration-dependent manner.
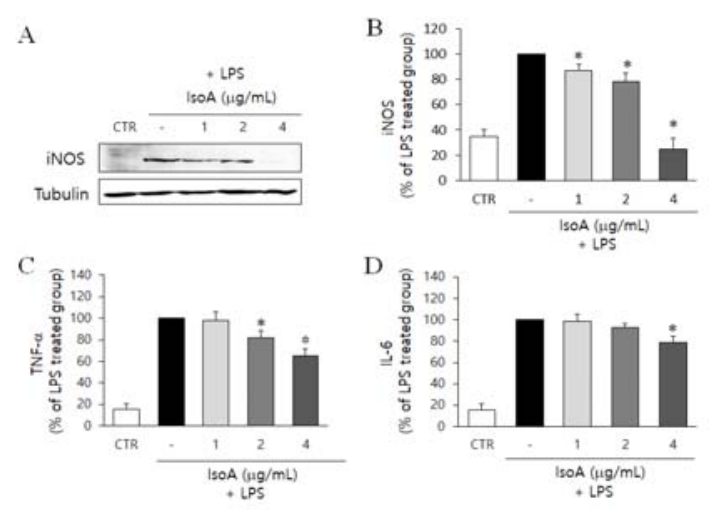

Figure 3: Effect of isoamericanin A (IsoA) on the expression of iNOS and pro-inflammatory cytokines in RAW cells. (A, B) The changes in iNOS expression in the presence of isoamericanin $A(1,2$, and $4 \mu \mathrm{g} / \mathrm{mL})$ were determined by western blot analysis. Graph showing the protein levels of iNOS. (C, D) The changes in TNF- $\alpha$ and IL- 6 pro-inflammatory cytokines in the presence of isoamericanin $A$ were determined by ELISA. Values are a percentage of the values for the LPS-treated groups, presented as mean \pm SD of three different experiments. ${ }^{*} p<0.05$, significantly different from the LPS-treated groups

\section{Inhibition of NF-kB activation isoamericanin A}

Western blot experiments were performed using specific antibodies to elucidate the effect of isoamericanin $A$ on LPS-induced NF-KB activation. As shown in Figure 4A, treatment of cells with LPS significantly increased the amount of NF-kB (p65 and p50) in the nucleus, indicating that LPS increased the translocation of NF-kB (p65 and p50) from the cytosol into the nucleus, whereas phosphorylated $\mathrm{I} K \mathrm{~K}(\mathrm{p}-\mathrm{I} \mathrm{K} B)$ in the cytosol was significantly increased. However, the pre-treatment of cells with isoamericanin A prior to LPS treatment reversed the effects of LPS on NF-KB translocation and IKB phosphorylation. Isoamericanin $A$ decreased the translocation of NF-KB p65 and p50 and reduced the amount of NF-KB p65 and p50 in the nucleus compared to LPS-treated control group. The treatment of cells with $4 \mu \mathrm{g} / \mathrm{mL}$ isoamericanin $A$ decreased the levels of NF-KB in the nucleus to close to that of the DMSO-treated control groups. In addition, isoamericanin $A$ inhibited the phosphorylation of IKB located in the cytosol and decreased the amount of $\mathrm{p}-\mathrm{I} \mathrm{KB}$ in a concentration-dependent manner.
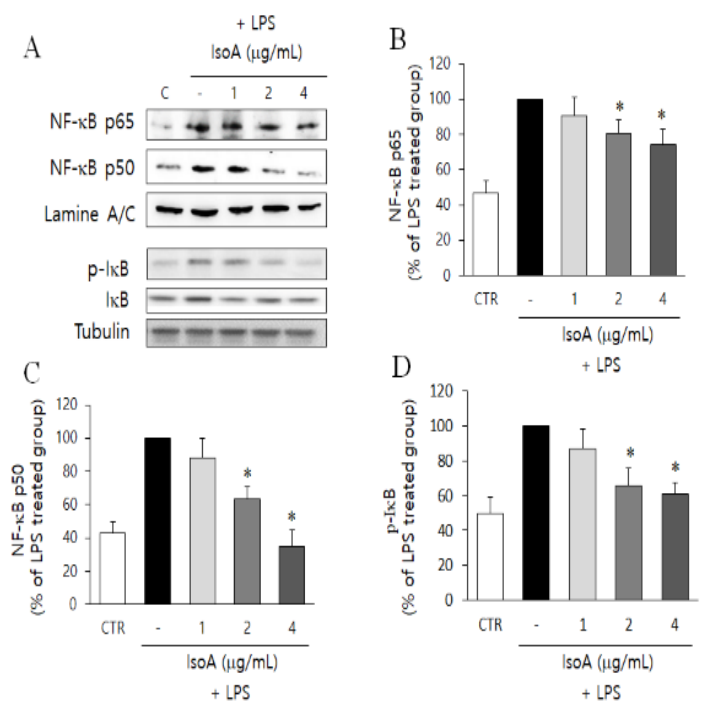

Figure 4: Effect of isoamericanin A (IsoA) on NF-kB activation in RAW cells. (A) The changes in NF-kB p65 and $\mathrm{p} 50$ in the nucleus, and in $\mathrm{p}-\mathrm{I} \mathrm{KB}$ and $\mathrm{IKB}$ in the cytosol were determined by western blot analysis. (B, C, D) Graphs showing the protein levels of NF-KB p65 and p50, p-IKB, and I $\mathrm{kB}$. Values are a percentage of the value for the LPS-treated groups. Data are presented as mean \pm SD of three different experiments. ${ }^{*} P<0.05$, significantly different from the LPS-treated groups

\section{DISCUSSION}

The stems and fruits of $O$. humifusa have been widely used as food and traditional medicines due to their beneficial effects on diabetes, arthritis, and inflammation [1]; the related biological activities have been reported. For example, the $\mathrm{MeOH}$ extract of $O$. humifusa 
stems exhibit anti-nociceptive and antiinflammatory effects [8]. The stems of 0 . humifusa significantly reduce serum totalcholesterol and blood-sugar levels in streptozotocin-induced diabetic rats [11]. The fruit of $O$. humifusa reduces the morphological changes observed in asthma, and suppresses UVB radiation-induced skin degeneration and non-melanoma skin carcinogenesis due to their anti-inflammatory effects $[12,13]$. The beneficial effects of $O$. humifusa on inflammation are accompanied by high antioxidant effects due to high levels of vitamin $\mathrm{C}$, polyphenols, and flavonoids present [14]. High levels of antioxidants in $O$. humifusa reduce the production of reactive oxygen species, decrease oxidative damage, and eventually alleviate oxidative stress in inflammation [15].

Conversely, reports regarding the biological activities of $O$. humifusa seeds are very limited. For example, the seed extract of $O$. humifusa alleviates osteoporosis [16] and decreases serum cholesterol and triglyceride contents [17] in ovariectomized rats because of the high polyphenol content in the seeds. Reports on the biological activities of $O$. humifusa are mostly limited to the plant's stems and fruits. Here, we report the anti-inflammatory effects of the seeds of $O$. humifusa and the isolation of the active constituent, isoamericanin A.

Isoamericanin A was first isolated from Phytolacca americana L. in 1987 [18]. Additionally, isoamericanin A was isolated from Brazilian Joannesia princeps [9] and barley tea [19]. Initially, isoamericanin A was identified as an inducer of prostaglandin 12 [18] or as an antioxidant constituent [19]. It was also reported to enhance choline acetyltransferase activity [20]. Other than the above, very few biological activities of isoamericanin A have been reported.

To the best of our knowledge, this is the first report regarding the potent anti-inflammatory effects of isoamericanin A against LPSstimulated RAW cells. Isoamericanin A effectively lowered the production of NO and proinflammatory cytokines, that was accompanied by the inhibition of NF-KB translocation. The NF$K B$ pathway plays crucial roles in human inflammatory diseases including rheumatoid arthritis, atherosclerosis, asthma, and inflammatory bowel disease [21-23]. The activation of NF-kB at inflammation sites increases the transcription of pro-inflammatory cytokines, chemokines, COX-2, and iNOS [24]. Therefore, NF-kB is a potential therapeutic target for inflammatory diseases.

\section{CONCLUSION}

The extract of $O$. humifusa seeds significantly reduces NO production in LPS-stimulated RAW cells, and isoamericanin A was identified as its active constituent. Isoamericanin A effectively lowers the production of $\mathrm{NO}$ as well as the expression of iNOS and pro-inflammatory cytokines. These effects are accompanied by decreased translocation of NF-kB from the cytosol to the nucleus and decreased phosphorylation of IKB in the cytosol induced by LPS. Thus, the seeds of $O$. humifusa and isoamericanin A have potential as antiinflammatory agents.

\section{DECLARATIONS}

\section{Acknowledgement}

This work was supported by research funds from Dankook University in 2019 to S.Y. Park.

\section{Conflict of interest}

No conflict of interest is associated with this work.

\section{Contribution of authors}

We declare that this work was done by the authors named in this article and all liabilities pertaining to claims relating to the content of this article will be borne by the authors. Ji Yun Yeo performed the experimental work. So-Young Park (SYP) and Kwang Woo Hwang designed the study and discussed the data. SYP analyzed the data and supervised the experimental work. All authors read and approved the final manuscript.

\section{Open Access}

This is an Open Access article that uses a funding model which does not charge readers or their institutions for access and distributed under the terms of the Creative Commons Attribution License (http://creativecommons.org/licenses/by/ 4.0) and the Budapest Open Access Initiative (http://www.budapestopenaccessinitiative.org/rea d), which permit unrestricted use, distribution, and reproduction in any medium, provided the original work is properly credited.

\section{REFERENCES}

1. Park CM, Kwak BH, Park SH, Hui Kim, Rhyu DY. Comparison of biological activities of Opuntia humifusa

Trop J Pharm Res, September 2020; 19(9): 1861 
and Opuntia ficus indica. Kor J Plant Res 2013; 26: 519525.

2. Hahm SW, Park J, Oh SY, Lee CW, Park KY, Kim H, Son YS. Anticancer properties of extracts from Opuntia humifusa against human cervical carcinoma cells. J Med Food 2015; 18: 31-44.

3. Hahm SW, Park J, Park KY, Son YS, Han H. Extracts of Opuntia humifusa Fruits Inhibit the Growth of AGS Human Gastric Adenocarcinoma Cells. Prevent Nutr Food Sci 2016; 21: 31-37.

4. Lee KS, Kim MG, Lee KY. Antimicrobial effects of the extracts of cactus Cheonnyuncho (Opuntia humifusa) against food borne pathogens. J Korean Soc Food Sci Nutr 2004; 33: 1268-1272.

5. Silva-Hughes $A F$, Wedge $D E$, Cantrell $C L$, Carvalho $C R$, Pan Z, Moraes RM, Madoxx VL, Rosa LH. Diversity and antifungal activity of the endophytic fungi associated with the native medicinal cactus Opuntia humifusa (Cactaceae) from the United States. Microbiol Res 2015; 175: 67-77.

6. Kang J, Lee J, Kwon D, Song Y. Effect of Opuntia humifusa supplementation and acute exercise on insulin sensitivity and associations with PPAR-gamma and PGC-1alpha protein expression in skeletal muscle of rats. Int J Mol Sci 2013; 14: 7140-7154.

7. Kang YJ, Kim HY, Lee C, Park SY. Nitric Oxide Inhibitory Constituents from Fruits of Opuntia humifusa. Nat Prod Sci 2014; 20: 211-215.

8. Sharma BR, Park CM, Choi JW, Rhyu D. Anti-nociceptive and anti-inflammatory effects of the methanolic extract of Opuntia humifusa stem. Avicenna J Phytomed 2017; 7: 366-375.

9. Waibel R, Benirschke G, Benirschke M, Achenbach $H$. Sesquineolignans and other constituents from the seeds of Joannesia princeps. Phytochemistry 2003; 62: 805811.

10. Kim HY, Hwang KW, Park SY. Extracts of Actinidia arguta stems inhibited LPS-induced inflammatory responses through nuclear factor-kappaB pathway in Raw 264.7 cells. Nutr Res 2014; 34: 1008-1016.

11. Hahm SW, Park J, Son YS. Opuntia humifusa stems lower blood glucose and cholesterol levels in streptozotocin-induced diabetic rats. Nutr Res 2011; 31: 479-487.

12. Lee SY, Bae CS, Choi YH, Seo NS, Na CS, Yoo JC, Cho SS, Park DH. Opuntia humifusa modulates morphological changes characteristic of asthma via IL-4 and IL-13 in an asthma murine model. Food Nutr Res 2017; 61: 1393307.
13. Lee JA, Jung BG, Kim TH, Lee SG, Park YS, Lee BJ. Dietary feeding of Opuntia humifusa inhibits UVB radiation-induced carcinogenesis by reducing inflammation and proliferation in hairless mouse model. Photochem Photobiol 2013; 89: 1208-1215.

14. Lee KS, Oh CS, Lee KY. Antioxidative effect of the fractions extracted from a cactus Chounyouncho (Opuntia humifusa). J Korean Soc Food Sci Nutr 2005; 37: 474-478.

15. Gasparrini M, Giampieri F, Forbes-Hernandez TY, Afrin $S$, Cianciosi D, Reboredo-Rodriguez $P$, Varela-Lopez A, Zhang J, Quiles JL, Mezzetti B. Strawberry extracts efficiently counteract inflammatory stress induced by the endotoxin lipopolysaccharide in Human Dermal Fibroblast. Food Chem Toxicol 2018; 114: 128-140.

16. Park J, Hahm SW, Son YS. Effects of Cheonnyuncho (Opuntia humifusa) seeds treatment on the mass, quality, and the turnover of bone in ovariectomized rats. Food Sci Biotechnol 2011; 20:1517-1524.

17. Hwang HJ, Kang MS, Kim BK, Jung B-M, Kim M. The effect of Opuntia humifusa seed extracts on platelet aggregation and serum lipid level in ovariectomized rats. J Life Sci 2012; 22:1680-168.

18. Hasegawa T, Fukuyama $Y$, Koshino K, Nakagawa $K$, Tori $M$, Asakawa $Y$. Structure of isoamericanin A, a prostaglandin 12 inducer, isolated from the seeds of Phytolacca americana L. Chem Lett 1987; 16: 329-332.

19. Etoh H, Murakami K, Yogoh T, Ishikawa H, Fukuyama Y, Tanaka H. Anti-oxidative compounds in Barley Tea. Biosci Biotechno. Biochem 2004; 68: 2616-2618.

20. Fukuyama Y, Hasegawa T, Toda M, Kodama M, Okazaki $H$. Structures of americanol $A$ and isoamericanol $A$ having a neurotrophic property from the seeds of Phytolacca Americana. Chem Pharm Bull 1992; 40: 252-254.

21. Wu $Y$, Wang F, Fan L, Zhang $W$, Wang $T$, Du $Y$, Bai $X$. Baicalin alleviates atherosclerosis by relieving oxidative stress and inflammatory responses via inactivating the NF-kappaB and p38 MAPK signaling pathways. Biomed Pharmacother 2018; 97: 1673-1679.

22. Huang W, Li ML, Xia MY, Shao JY. Fisetin-treatment alleviates airway inflammation through inhibition of MyD88/NF-kappaB signaling pathway. Int J Mol Med 2018; 42: 208-218.

23. Han Z, Boyle DL, Manning AM, Firestein GS. AP-1 and $N F-k a p p a B$ regulation in rheumatoid arthritis and murine collagen-induced arthritis. Autoimmunity 1998; 28: 197208.

24. Tak PP, Firestein GS. NF-kappaB: a key role in inflammatory diseases. J Clin Invest 2001; 107: 7-11. 